\title{
Monitoring Device
}

National Cancer Institute

\section{Source}

National Cancer Institute. Monitoring Device. NCI Thesaurus. Code C41278.

A recording device or display that continuously keeps track of the function, condition, or operation of the system or organism and warns of an abnormal or potentially dangerous situation. 